\title{
Het raadplegen van individuele feedback op de voortgangstoets door Nijmeegse studenten geneeskunde
}

\author{
A.J.N.M. Thoben, R.R.M. Leunissen, J.C.G. Jacobs, R.S.G. Holdrinet
}

\section{Samenvatting}

Inleiding: De interfacultaire voortgangstoets is sinds 1995 ook in het Nijmeegse geneeskundecurriculum ingevoerd. Andere participerende universiteiten zijn naast Maastricht, Groningen en Leiden. Vanaf 2000 wordt in het UMC St Radboud via de webpagina een individuele feedback op de voortgangstoets aangeboden aan studenten. Dit was aanleiding tot de volgende vraagstellingen: (1) Hoeveel studenten raadplegen de individuele voortgangstoetsanalyses?; (2) Is er verschil in de frequentie van raadplegen tussen studenten met een onvoldoende en een voldoende score op de voortgangstoets?; (3) Verschillen de jaargroepen van studenten in raadplegen?

Methode: De inloggegevens werden verzameld van studenten die de analyses raadpleegden van de voortgangstoetsen van december 2002, maart 2003 en mei 2003. Deze gegevens werden vergeleken met het toetsresultaat (voldoendelonvoldoende) en jaargroepnummer van de betreffende studenten.

Resultaten: Gemiddeld 45\% van alle studenten raadpleegde de voortgangstoetsanalyse. Er bestond geen significant verband tussen het toetsresultaat en het raadplegen van de analyse. De data wijzen erop dat in de loop van de studie daarin geen veranderingen optreden.

Conclusies en discussie: Individuele feedback op de voortgangstoets via een webpagina is een laagdrempelige innovatie. Rond $45 \%$ van de studenten maakt gebruik van de feedback. Studenten met een onvoldoende doen dit niet vaker dan studenten met een voldoende. De analyses op de voortgangstoets bieden studenten de mogelijkheid meer verantwoordelijkheid te nemen voor hun eigen leerproces. Het is wenselijk dat zowel studenten als docenten belangrijk meer gebruik maken van de feedbackmogelijkheden die deze toets biedt. (Thoben AJNM, Leunissen RRM, Jacobs JCG, Holdrinet RSG. Het raadplegen van individuele feedback op de voortgangstoets door Nijmeegse studenten geneeskunde. Tijdschrift voor Medisch Onderwijs 2006;25(3):125-133.)

\section{Inleiding}

De interfacultaire voortgangstoets geneeskunde is in 1976 ontwikkeld en in 1977 geïmplementeerd in het geneeskundecurriculum van de Universiteit Maastricht. De toets test kennis op het niveau van een basisarts en wordt gelijktijdig, viermaal per jaar, in een identieke versie voorgelegd aan alle studenten van jaar $1 \mathrm{t} / \mathrm{m} 6$. Het gaat om 250 vragen over het hele gebied van de geneeskunde: klinische vakken, basisvakken en sociaal-medische vakken. De vragen hebben tot nog toe (studiejaar 2004-2005) het karakter van een stelling met de antwoordalternatieven 'juist', 'onjuist' of open ('weet niet'). De belangrijkste motivatie om destijds de voortgangstoets te introduceren, was het voorkómen van toetsgestuurd leergedrag. ${ }^{1-3}$ Daarnaast kan de voortgangstoets fungeren als een op feitenkennis gerichte aanvulling op de bloktoetsing, zodat in de bloktoetsen meer aandacht besteed kan worden aan het toetsen van inzicht en vaardigheden.

Op dit moment heeft de voortgangstoets een interfacultair aspect: naast de Universiteit Maastricht maken ook het UMC St Radboud Nijmegen, de Rijksuniversiteit 
Groningen en het Leids Universitair Medisch Centrum gebruik van deze toets. De Universiteit Maastricht, het UMC St Radboud Nijmegen en de Rijksuniversiteit Groningen participeren in de productie van de voortgangstoetsen, terwijl het Leids Universitair Medisch Centrum hier niet aan deelneemt. ${ }^{3-5}$ Ook in het buitenland gebruikt men aan enkele universiteiten voortgangstoetsen (University of Missouri, VS; McMaster University, Hamilton, Canada). 6

De interfacultaire voortgangstoets geneeskunde levert informatie die op diverse niveaus kan worden benut:

1. Op curriculumniveau kan de opleidingscommissie of de curriculumcoordinator nagaan hoe de ontwikkeling van de scores van de studenten per jaargroep verloopt en deze vergelijken met de prestaties elders.

2. Ook zijn de wijze waarop de scores verdeeld zijn over de verschillende disciplines (zoals anatomie, chirurgie, medische psychologie), bundelingen van disciplines (basiswetenschappen, gedragswetenschappen, kliniek) en categorieën (ziekten van de luchtwegen, leeftijdsfasen, kennis over vaardigheden) te zien.

3. Docenten kunnen zien hoe vragen over door hen behandelde onderwerpen beantwoord worden door eigen studenten en studenten van elders.

4. Ook kan de individuele analyse van de voortgangstoets de studenten informeren over hun studievoortgang qua feitenkennis ${ }^{2} 6$ en kan de studieadviseur deze gebruiken bij de begeleiding van de student. Hierdoor worden de formatieve kwaliteiten van de toets beter benut.

Bij een peiling in 1995 van het studentenoordeel in Maastricht met een schriftelijke enquête gaf $38 \%$ van de studenten aan dat de resultaten op de verschillende voortgangstoetsonderdelen hun studieactiviteiten beïnvloedden. ${ }^{7}$

Vanaf de start van het nieuwe curriculum in Nijmegen in 1995 werden de voortgangstoetsanalyses uitgeprint en overhandigd aan studenten die deze kwamen afhalen bij het Studenten-InformatiePunt. Ongeveer 50\% van de beschikbare papieren analyses bleef achter. Sinds 2000 worden de analyses uitsluitend elektronisch beschikbaar gesteld via de studenteningang van de UMCN-webpagina (zie figuren 1.1 en 1.2). Dit werd mogelijk door vanuit de studentenwebpagina een link aan te brengen naar het reeds beschikbare bestand met de betreffende gegevens. Het via een webpagina aanbieden van gestructureerde individuele feedback op een schriftelijke toets is in het medisch onderwijs weinig beschreven, ${ }^{8}$ maar met de huidige technologische mogelijkheden lijkt zo'n aanpak een waardevolle vorm van feedback te zijn. De voortgangstoetsanalyse biedt studenten namelijk de mogelijkheid om inzicht te verkrijgen in hun prestaties ten opzichte van andere studenten in de jaargroep en geeft hen een overzicht van hun kennisontwikkeling door de jaren heen met gedetailleerde informatie op onderdelen van disciplines en/of ziektecategorieën.

\section{Aanleiding tot het onderzoek en vraag- stellingen}

Studenten zijn vrij om al dan niet gebruik te maken van de aangeboden voortgangstoetsanalyse. Bij de begeleiding van studenten geneeskunde in Nijmegen met problemen bij de voortgangstoets viel het de studieadviseurs op dat deze studenten vaak geen kennis namen van de individuele analyses van hun prestaties op de voortgangstoets. Dit was aanleiding om na te gaan hoe vaak de analyses feitelijk werden geraadpleegd. In een eerdere enquête naar het studentenoordeel over de voortgangs- 
Het raadplegen van individuele feedback op de voortgangstoets $\mid$ A.J.N.M. Thoben et al.

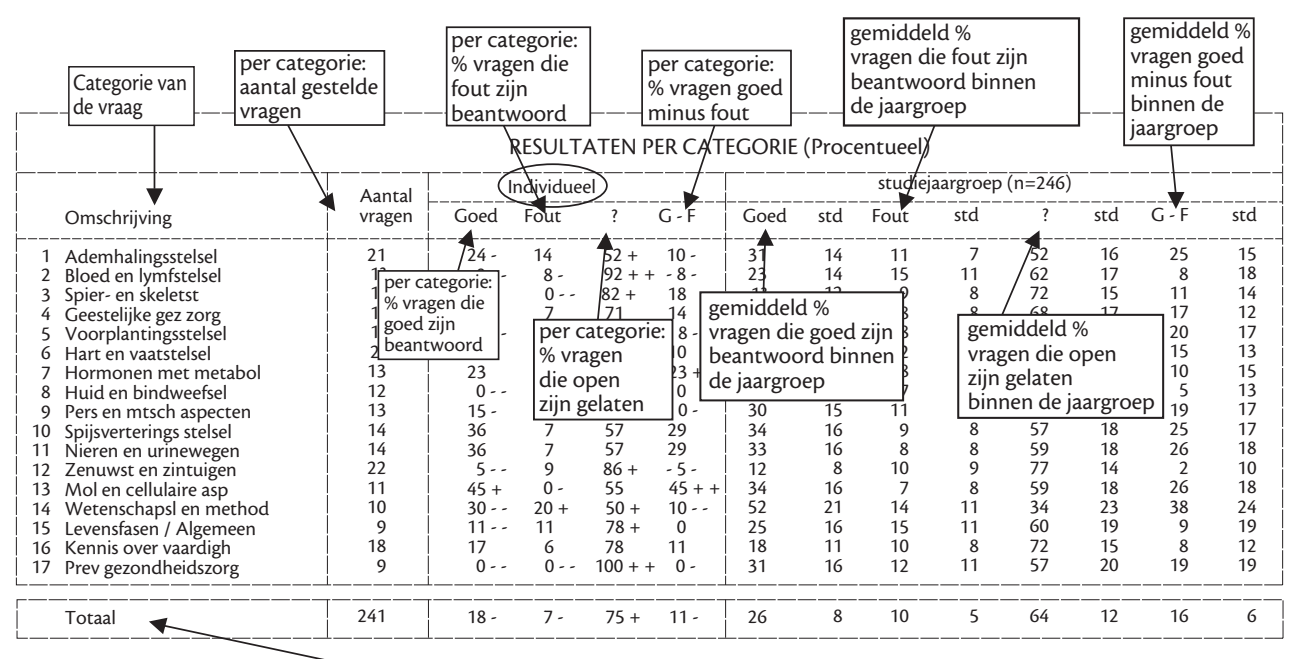

$-1--1+1++/$ laag resp. hoog in vergetijking tot totale groep

De norm voor VOLDOENDE is voor deze toets: $11,21 \quad \begin{aligned} & \text { resultaten } \\ & \text { voor gehele } \\ & \text { toon }\end{aligned}$

\begin{tabular}{ll|l} 
De norm voor GOED is voor deze toets: & 21.65 & voor \\
Uw procentuele GOED - Fout score is: & 11.20 (Absoluut: 27$)$ & toets
\end{tabular}

Uw procentuele GOED - Fout sco

toets

Niet opgenomen vragen: $40,59,71,72,77,138,139,152$ en 168

Sleutelverwijzingen : Geen

NOTA BENE: een zelfde overzicht is beschikbaar verdeeld over de 6 basisvakken, 10 klinische vakken, 4 gedragswetenschappelijke overige vakken

Figuur 1.1 Leeswijzer bij de individuele analyse voortgangstoets.

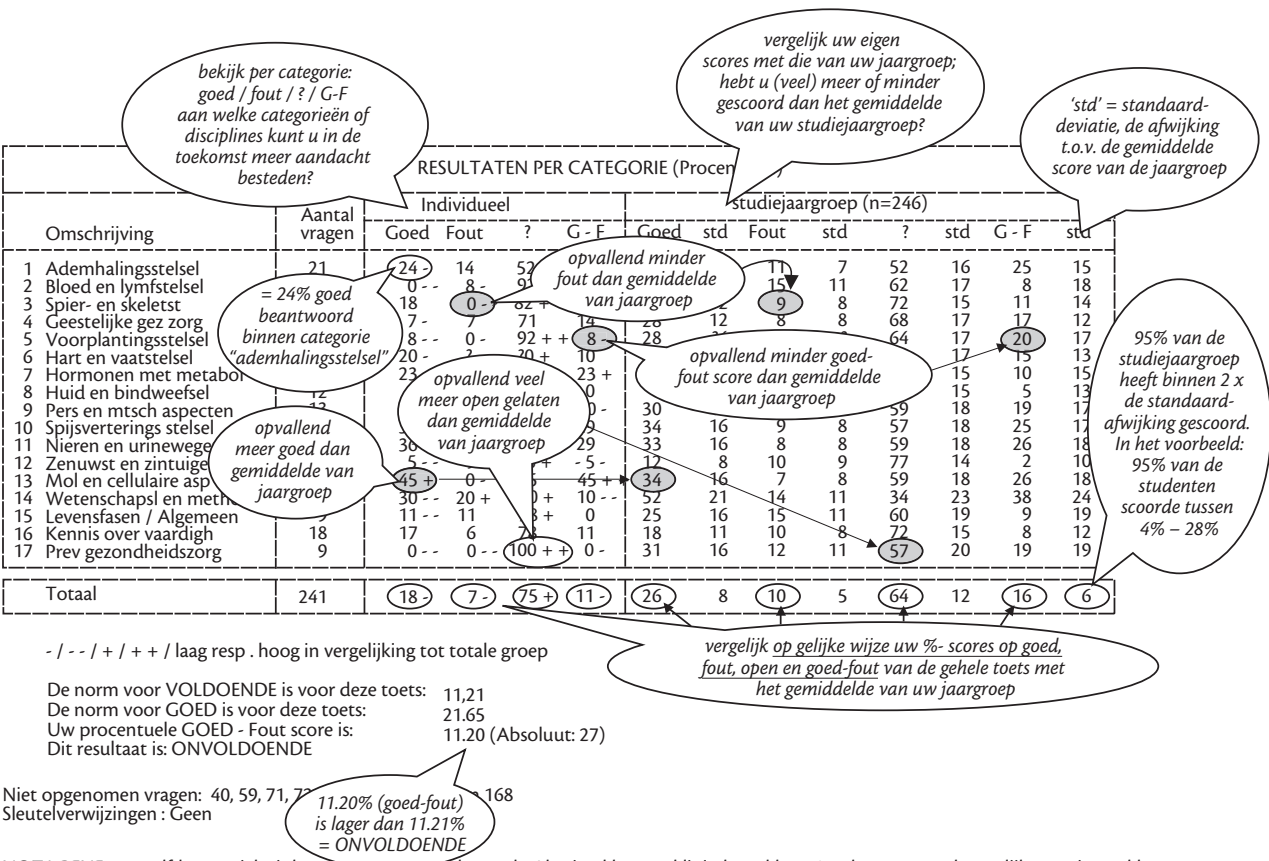

NOTA BENE: een zelfde overzicht is beschtruar verueeld over de 6 basisvakken, 10 klinische vakken, 4 gedragswetenschappelijke overige vakken

Figuur 1.2 Toelichting bij de individuele analyse voortgangstoets. 
Tabel 1 Stellingen uit de gebruikersenquête over de voortgangstoets (2003).8

Stelling 1: “lk gebruik het uitslagoverzicht om na te gaan op welke categorieën of vakgebieden ik goed
en minder goed scoor."
\begin{tabular}{llllll} 
Altijd & Vaak & Soms & Nooit & Totaal & Niet ingevuld \\
\hline $193(17 \%)$ & $354(31 \%)$ & $296(26 \%)$ & $307(27 \%)$ & $1150(100 \%)$ & 18
\end{tabular}

Stelling 2: "De voortgangstoetsanalyse beïnvloedt mijn wijze van studeren."

\begin{tabular}{llllll} 
Zeer sterk & Behoorlijk & Weinig & Helemaal niet & Totaal & Niet ingevuld \\
\hline $9(1 \%)$ & $109(9 \%)$ & $303(26 \%)$ & $730(63 \%)$ & $1151(100 \%)$ & 17 \\
\hline
\end{tabular}

toets in Nijmegen, gehouden in 2003, werd aan studenten gevraagd of (1) zij de individuele analyses raadpleegden en of (2) dit effect had op hun studieactiviteiten. ${ }^{9}$ Bijna de helft van de studenten (48\%) gaf aan de individuele analyse altijd of vaak te raadplegen, een kwart van de studenten deed dit soms, en ruim een kwart meldde dit nooit te doen (zie tabel 1). Verder gaf $10 \%$ van de studenten aan dat het raadplegen van de feedback de wijze van studeren behoorlijk tot sterk beïnvloedde en voor $25 \%$ van de studenten was dit in beperkte mate het geval. Dit komt overeen met de bevindingen in Maastricht. ${ }^{7}$

De enquêtegegevens waren aanleiding om de beschikbare inloggegevens te analyseren. Hierbij werden de volgende onderzoeksvragen geformuleerd:

1. Hoeveel studenten raadplegen de individuele voortgangstoetsanalyses?

2. Bestaat er verschil in de frequentie van raadplegen tussen studenten met een onvoldoende en een voldoende score op de voortgangstoets?

3. Bestaat er verschil in de frequentie van raadplegen tussen de jaargroepen van studenten?

\section{Methode}

De inloggegevens werden verzameld van studenten die de analyses raadpleegden van de voortgangstoetsen van december 2002, maart 2003 en mei 2003. Indien één student een bepaalde analyse meer- dere malen raadpleegde, werd dit als één raadpleging geteld. Deze gegevens werden vergeleken met het toetsresultaat (voldoende/onvoldoende) van de betreffende studenten. Om te toetsen of er een relatie bestond tussen het wel/niet raadplegen van de analyses en de toetsresultaten, werd gebruik gemaakt van de $\chi 2$-toets. Verder werden per voortgangstoets de frequenties van raadplegen per jaargroep grafisch weergegeven.

\section{Resultaten}

Uit de tabellen 2.1, 2.2 en 2.3 blijkt dat gemiddeld $45 \%$ van alle studenten de analyse raadpleegde. Voor elk van de drie voortgangstoetsen werd nagegaan of er verschil bestond in raadplegen tussen de totale groep studenten met een onvoldoende en de totale groep met een voldoende score. Er bestond geen significant verband tussen het behaalde toetsresultaat en het raadplegen van de individuele voortgangstoetsanalyses. Voor de voortgangstoets van december 2002 was $\chi 2$ .094 ( $\mathrm{df}=1$; n.s.), voor de voortgangstoets van maart 2003 was $\chi 2.564$ ( $\mathrm{df}=1$; n.s.) en voor de voortgangstoets van mei 2003 was $\chi 21.375$ (df=1; n.s.).

In figuur 2 zijn de frequenties van raadplegen per jaargroep voor iedere voortgangstoets afzonderlijk weergegeven. Afgezien van jaargroep 5 uit de voortgangstoets van mei 2003, een onverklaarde uitzondering, blijken er geen grote ver- 
Tabel 2.1 Voortgangstoets december 2002.

\begin{tabular}{lccc}
\hline & Onvoldoende & Voldoende & Totaal \\
Raadplegers & 104 & 529 & $633(50 \%)$ \\
Niet-raadplegers & 99 & 525 & $624(50 \%)$ \\
\cline { 2 - 4 } Totaal & $203(16 \%)$ & $1054(84 \%)$ & 1257 \\
\hline
\end{tabular}

$\chi^{2}(\mathrm{df}=1)=.094$, n.s.

Tabel 2.2 Voortgangstoets maart 2003.

\begin{tabular}{lccc}
\hline & Onvoldoende & Voldoende & Totaal \\
Raadplegers & 98 & 420 & $518(42 \%)$ \\
Niet-raadplegers & 124 & 599 & $723(58 \%)$ \\
\cline { 2 - 4 } Totaal & $222(18 \%)$ & $1019(82 \%)$ & 1241 \\
\hline
\end{tabular}

$\chi^{2}(\mathrm{df}=1)=.564$, n.s.

Tabel 2.3 Voortgangstoets mei 2003.

\begin{tabular}{lccc}
\hline & Onvoldoende & Voldoende & Totaal \\
Raadplegers & 58 & 461 & $519(44 \%)$ \\
Niet-raadplegers & 60 & 605 & $665(56 \%)$ \\
\cline { 2 - 4 } Totaal & $118(10 \%)$ & $1066(90 \%)$ & 1184 \\
\hline
\end{tabular}

$\chi^{2}(\mathrm{df}=1)=1.375$, n.s.

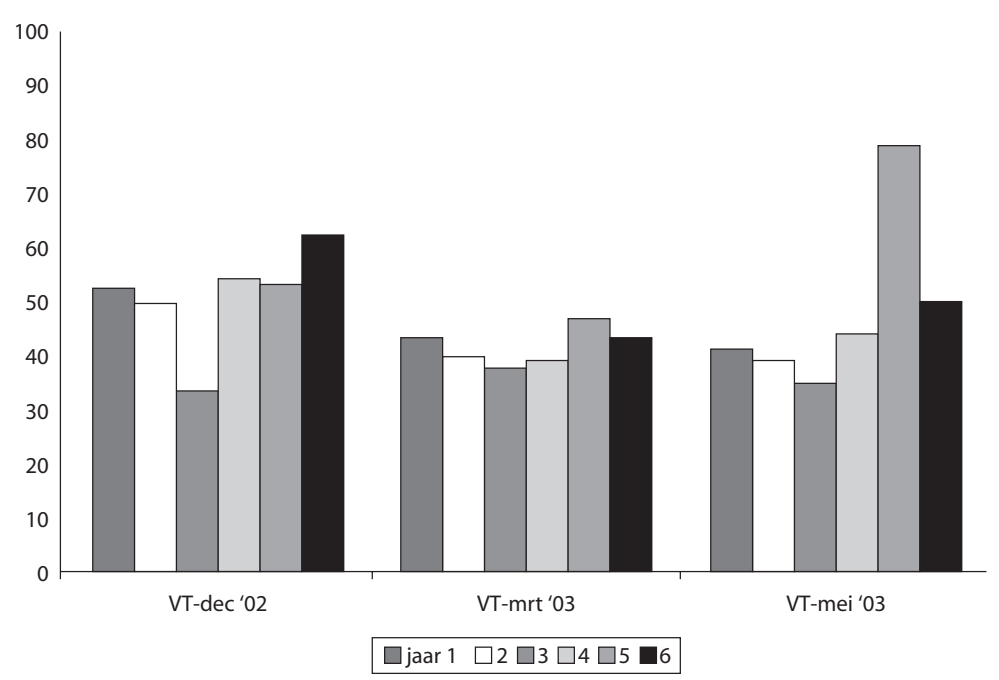

Figuur 2 Percentage studenten per jaargroep dat de voortgangstoetsanalyses van december 2002, maart 2003 en mei 2003 raadpleegde. 
schillen of tendensen gerelateerd aan het jaargroepnummer te zijn.

\section{Conclusies en discussie}

De studentenwebpagina met VT-informatie is een belangrijke faciliterende en laagdrempelige innovatie. De bijbehorende kosten zijn gering in vergelijking met de productie van een geprinte versie die persoonlijk uitgereikt wordt of per post verstuurd wordt.

De analyses van de voortgangstoets die via de webpagina toegankelijk zijn, werden door iets minder dan de helft van de studenten geraadpleegd. De inloggegevens over het raadplegen van de feedback zijn in overeenstemming met de resultaten van de eerder afgenomen studentenenquête. Een belangrijke constatering is dat er geen verband bestaat tussen het raadplegen door studenten met een onvoldoende dan wel voldoende toetsresultaat. Hoewel er geen longitudinale data verzameld zijn, wijzen de beschikbare data erop dat er geen veranderingen optreden in het raadplegen van de feedback in de loop van de studie.

Het niet raadplegen van de feedback op de voortgangstoets kan betekenen dat studenten weinig belang hechten aan de voortgangstoets. Mogelijk hangt dit samen met het geringe aantal studiepunten dat verbonden is aan de voortgangstoets en/of met het relatief beperkte belang bij het behalen van propedeuse, doctoraal en artsexamen. De Nijmeegse Voortgangstoetscommissie bepleit daarom zowel het aantal studiepunten te vergroten voor de voortgangstoets als het gewicht van de voortgangstoetsen in de Onderwijs- en Examenregeling.

Is de voortgangstoets met haar individuele analyse wel geschikt als instrument voor feedback? Wanneer je de resultaten van toetsing wilt gebruiken om studieactiviteiten van de student te beïnvloeden, gelden een aantal eisen: 13
Feedback moet snel genoeg beschikbaar zijn om nog van nut te zijn en dient vaak en gedetailleerd genoeg gegeven te worden.

De antwoordsleutel is al beschikbaar drie uren na het afsluiten van de toets, het toetsboekje blijft eigendom van de student, terwijl de individuele analyse na iets meer dan vier weken beschikbaar komt (vergelijkbaar met de uitslag van kernbloktoetsingen). De antwoordsleutel geeft feedback over individuele items c.q. onderwerpen of thema's; de analyse geeft aanvullend informatie over de disciplines en categorieën waarop goed of slecht gescoord werd.

Feedback moet op het leren van de student gericht zijn, moet begrijpelijk zijn voor de studenten en dient verbonden te zijn met de doelstellingen van de opdracht en de gehanteerde criteria.

De antwoordsleutel en de analyse zijn begrijpelijk, direct te gebruiken bij het studeren, de doelstellingen van de voortgangstoets zijn grotendeels gekoppeld aan het raamplan14 en daarmee aan de opleiding, en de normen zijn in de VT-regeling geëxpliciteerd.

Studenten moeten ook met behulp van de feedback hun prestatie kunnen verbeteren. De feedback op de voortgangstoets voldoet ons inziens in redelijke mate aan deze eisen.

De antwoordsleutel voorziet de studenten bij elk getoetst onderwerp van een literatuurverwijzing waarmee ze relevante informatie kunnen opzoeken.

Een ander argument voor het niet raadplegen van de feedback dat vaak door studenten wordt genoemd, is dat de analyses slecht leesbaar zouden zijn. Om hieraan tegemoet te komen is er op de studentenwebpagina over de voortgangstoets een voorbeeld van een analyse beschikbaar ge- 
steld, voorzien van grafisch weergegeven aanvullende informatie ${ }^{15}$ (zie ook figuren 1.1 en 1.2). Een grondiger analyse stelt de student in staat om zelf meer verantwoordelijkheid te nemen voor de bewaking van zijn/haar leerproces en kennisontwikkeling, meer aandacht dus voor de metacognitieve vaardigheden. Om dit te bevorderen is extra voorlichting nodig die studenten wijst op de waarde van de feedback op de voortgangstoets voor hun persoonlijke leeractiviteiten. Anderzijds zou het onderwijsmanagement meer consequenties kunnen verbinden aan het niet raadplegen van de feedback. Nu is er veel vrijblijvendheid en speelt de individuele verantwoordelijkheid van de student een grote rol. Zo is het mogelijk dat een student met een krappe 5 voor het blok Voortplanting het doctoraal examen haalt (enkele vijven zijn toegestaan), vervolgens doorstroomt naar het artsexamen en later de studieadviseur raadpleegt wegens het niet behalen van de laatste voortgangstoetsen met o.a. een lage score voor gynaecologie/obstetrie. Wanneer de analyses per student opgenomen worden in een portfoliosysteem ${ }^{10}$ dat adequaat begeleid wordt door een mentorcoach, is het belangrijk dat een student meer verantwoordelijkheid neemt voor het corrigeren van de kennishiaten. Onder andere om in de laatstgenoemde situatie verbetering aan te brengen, is in het Nijmeegse bachelor-mastercurriculum dat in 2005 van start is gegaan ruimte gecreëerd voor een jaarlijks 'voortgangsgesprek'. Tijdens dat gesprek zal de mentor-coach expliciet met de student samen kijken naar de resultaten die werden behaald op de voortgangstoets. ${ }^{12}$

Tot slot, kwantitatieve gegevens betreffende het raadplegen van de voortgangstoetsanalyse zijn interessant. Maar 'raadplegen' is niet per se gelijk aan 'bestuderen'. ${ }^{8}$ De Nijmeegse Voortgangstoetscommissie is daarom benieuwd naar de ervaringen die zullen worden opgedaan met de voortgangsgesprekken op basis van het portfolio die in 2006 van start zullen gaan.

\section{Naschrift}

Sinds 1 september 2005 is het voor alle geneeskundestudenten mogelijk om hun

Tabel 3 Raadplegingsgegevens van enkele voortgangstoetsen per 1 maart 2006.

\begin{tabular}{lrrrrrr}
\hline Voortgangstoets & Mrt03 & Mei03 & Mrt05 & Mei05 & Sept05 & Dec05 \\
\hline Totaal aantal deeInemers & 1241 & 1184 & 1471 & 1372 & 1578 & 1585 \\
\hline Raadplegers in de maanden & & & & & & \\
April 2005 & 8 & 9 & 26 & & & \\
Mei 2005 & 15 & 19 & 1051 & & & \\
Juni 2005 & 8 & 7 & 272 & 921 & & \\
Juli 2005 & 0 & 2 & 54 & 210 & & \\
Augustus 2005 & 2 & 3 & 56 & 167 & & \\
September 2005 & 5 & 10 & 181 & 317 & & \\
Oktober 2005 & 5 & 5 & 80 & 137 & & \\
November 2005 & 7 & 9 & 119 & 161 & $2344^{*}$ & \\
December 2005 & 7 & 6 & 111 & 140 & 919 & \\
Januari 2006 & 4 & 7 & 69 & 63 & 492 & 1647 \\
Februari 2006 & 2 & 4 & 50 & 50 & 169 & 650 \\
\hline
\end{tabular}

* In november 2005 werd een webdossiercursus gegeven aan eerstejaars studenten tijdens welke de studenten ook geattendeerd werden op de voortgangstoetsanalyses in het webdossier. 
eigen elektronisch webdossier in te zien. Daarin staan o.a. alle onderwijsroostergegevens, alle behaalde studieresultaten, en ook zijn daarin de individuele voortgangstoetsanalyses opgenomen. Studenten raadplegen dit dossier vrijwel dagelijks. In tabel 3 staan de voortgangstoets-raadpleegcijfers per maand van enkele oudere en enkele recente voortgangstoetsen. Het blijkt dat - gemiddeld gezien - de analyses van de voortgangstoetsen van september en december 2005 ruwweg door iedere student tenminste éénmaal werden geraadpleegd. Dat is een duidelijke toename vergeleken met de cijfers uit 2002-2003 in dit artikel. Ook de wat oudere voortgangstoetsen (tot ongeveer één jaar in het verleden) worden heel regelmatig ingezien. Voortgangstoetsen die langer dan één jaar geleden werden afgelegd (voorbeeld: maart en mei 2003) worden nog slechts enkele malen per maand bekeken. Aan het eind van het studiejaar 2005-2006 zal het voortgangsgesprek plaatsvinden met de mentor-coach waarin aandacht zal worden besteed aan de voortgangstoetsresultaten. Te verwachten valt dat voorafgaand daaraan wederom de voortgangstoetsanalyses intensief geraadpleegd zullen worden.

\section{Literatuur}

1. Verwijnen GM, Pollemans MC, Wijnen WHFW. Voortgangstoetsing. In: Metz JCM, Scherpbier AJJA, Vleuten CPM van der, editors. Medisch Onderwijs in de Praktijk. Assen: Van Gorcum; 1995. p. 225-32.

2. Vleuten CPM van der, Verwijnen GM, Wijnen WHFW. Fifteen years of experience with progress testing in a problem-based learning curriculum. Med Teach 1996;18(2):103-9.

3. Verhoeven BH. Progress testing: the utility of an assessment concept [dissertation]. Maastricht: Universiteit Maastricht: 2003.

4. Bulte JA, Ket P. Invoeren van de Maastrichtse voortgangtoets in andere faculteiten: $\mathrm{J} / \mathrm{O} /$ ? (Forum 1). Tijdschrift voor Medisch Onderwijs 2000;19(1):31-7.

5. Vleuten CPM van der, Verwijnen GM, Holdrinet RSG, Oeseburg B, Bulte JA, Leunissen RRM. Naar een interfacultaire voortgangstoets. Resul- taten van proefafnames. Bulletin Medisch Onderwijs 1995;15:1-7.

6. Blake JM, Norman GR, Keane DR, Mueller CB, Cunnington J, Didyk N. Introducing progress testing in McMaster University's problem-based medical curriculum: psychometric properties and effect on learning. Acad Med 1996;71(9):1002-7.

7. Linden ML, Brümmer I, Hoogenboom RJI, Scherpbier AJJA, Verwijnen GM. De Maastrichtse voortgangstoets. Een vergelijking van drie peilingen van het consumentenoordeel. Bulletin Medisch Onderwijs 1995;14:186-91.

8. Vleuten $\mathrm{C}$ van der, Schuwirth L, Muijtjens A, Driessen E. De rol van ICT in studietoetsen, een verkenning. In: Heijnen G, Meeder S, editors. Toetsen en ICT in het hoger onderwijs (SURF). Utrecht: Volta; 1999. p. 7-15.

9. Evaluatierapport voortgangstoetsing: interne rapportage UMC St Radboud (maart 2003).

10. Driessen EW, Tartwijk J van, Vermunt JD, Vleuten CPM van der. Use of portfolios in early undergraduate medical training. Med Teach 2003;25(1):1823.

11. Berkel H, Bax A, editors. Toetsen in het hoger onderwijs. Houten/Diegem: Bohn Stafleu van Loghum; 2002. p. 192.

12. Stuurgroep bachelor/master-structuur geneeskunde. Competente student, competente arts. Plan voor de bachelor/master-structuur in de Nijmeegse studie geneeskunde. Nijmegen: UMC St Radboud; 2005. p. 32.

13. Gijbels D, Watering $G$ van de, Dochy F. Op weg naar een integratie van leren, instructie en toetsing. Tijdschrift Onderzoek van Onderwijs 2005;34(4):56.

14. Verhoeven BH, Buijs C, Scherpbier AJJA, Verwijnen GM. De Maastrichtse voortgangstoets getoetst aan het Raamplan. Bulletin Medisch Onderwijs 1998;17:108-17.

15. Toelichting individuele analyse VT 2005-2006 [homepage op internet]. Nijmegen: UMC St Radboud [geciteerd 11 mei 2006]. Beschikbaar op: http://www.umcn.nl/student.

De auteurs:

Drs. A.J.N.M. Thoben is arts en als beleidsmedewerker voor de Voortgangstoetscommissie werkzaam bij de afdeling Onderwijs en StudentenZaken, Onderwijsinstituut van het UMC St Radboud te Nijmegen.

Drs. R. Leunissen is hoofd OnderwijsSystemen en Automatisering, Onderwijsinstituut van het UMC St Radboud te Nijmegen.

Mw. drs. J.C.G. Jacobs, arts en onderwijskundige, was destijds onderzoeker bij de afdeling Ontwikkeling en Onderzoek van Medisch Onderwijs van het Onderwijsinstituut van het UMC St Radboud te Nijmegen. Zij werkt $n u$ als beleidsmedewerker bij het Onderwijsinstituut van het VUmc, Amsterdam. 
Prof. dr. R.S.G. Holdrinet is internist-hematoloog en hoogleraar Medisch Onderwijs, Onderwijsinstituut van het UMC St Radboud te Nijmegen.

Correspondentieadres:

Drs. A.J.N.M. Thoben, UMC St Radboud, Onderwijs- en Studentenzaken 101 OSZ, Postbus 9101, 6500 HB Nijmegen,a.thoben@osz.umcn.nl.
Belangenconflict: geen gemeld.

Financiële ondersteuning: geen gemeld.

\section{Summary}

Introduction: In 1995 progress testing was introduced in the Nijmegen undergraduate medical curriculum. The medical schools of Groningen, Leiden, Maastricht and Nijmegen collaborate on progress testing and use the same progress tests for all their students. Since 2000, University Medical Center Nijmegen has posted feedback on individual students' progress test results on the website. We examined: 1) how many students consult the feedback and 2) whether consultation of feedback was associated with passing or failing the test or 3) year of training.

Method: Login data from students who consulted the web-based feedback on the progress tests of December 2002, March 2003, and May 2003 were collected and analysed. The data were compared with test results (pass/fail) and year of training.

Results: On average 45\% of all the Nijmegen students consulted the feedback. The percentages of students who consulted the feedback did not differ between students who passed and students who failed a test. Except for a high percentage of Year 5 students who consulted the results of the test in May 2003, consulting frequency showed no change with year of training.

Conclusion: Web-based, individual feedback on progress test results is an easily accessible innovation. The test analyses were accessed by about $45 \%$ of the students. A pass or fail result was not related to feedback consultation. Progress test analyses offer students the opportunity to take more responsibility for their own learning processes. We recommend that both students and teachers should take more advantage of this opportunity. (Thoben AJNM, Leunissen RRM, Jacobs JCG, Holdrinet RSG. Consultation of individual feedback on progress test results by Nijmegen medical students. Dutch Journal of Medical Education 2006;25(3):125-133.) 